Article

\title{
Preparation of Cross-Linkable Waterborne Polyurethane-Acrylate Coating Films with Multifunctional Properties
}

\author{
Xin Chen ${ }^{1,2,+}$, Xiaomin Ye ${ }^{3,+}$, Lulu Lu ${ }^{4}$, Yudan Qian ${ }^{2}$, Lingnan Wang ${ }^{5}$, Yicheng Bi ${ }^{6}$, \\ Zefeng Wang ${ }^{2,7, *}$ and Zaisheng Cai ${ }^{1, *}$ \\ 1 Key Laboratory of Science and Technology of EcoTextile, Donghua University, Ministry of Education, \\ Shanghai 201620, China; chenxin850526@163.com \\ 2 Department of Chemistry, Lishui University, Lishui 323000, China; qydycy321414@163.com \\ 3 Scientific Research Center, Wenzhou Medical University, Wenzhou 325035, China; yexiaomin22@163.com \\ 4 School of Biological Science and Engineering, South China University of Technology, Guangzhou 510640, \\ China; 15068883939@163.com \\ 5 Wenzhou Institute, University of Chinese Academy of Sciences (Wenzhou Institute of Biomaterials \& \\ Engineering), Wenzhou 325001, China; wangln07@163.com \\ 6 Electromechanical Engineering College, Qingdao University of Science \& Technology, Qingdao 260061, \\ China; biyicheng521@126.com \\ 7 Post-Doctoral Research Station, Dalian Zhenbang Fluorocarbon Paint Stock Co., Ltd., Dalian 116036, China \\ * Correspondence: shangk72@163.com (Z.W.); zshcai@dhu.edu.cn (Z.C.) \\ + These two authors contributed equally to this paper.
}

Received: 15 December 2019; Accepted: 3 January 2020; Published: 11 January 2020

check for updates

\begin{abstract}
Self-migration or unstable phase inversion occurs when the application conditions are varied, which limits the application of polyurethane-acrylate (PUA) composite films. In this paper, cross-linked polyurethane/poly(methyl methacrylate-co-borneol acrylate) shell microspheres were prepared by using the seeded emulsion polymerization method. The core-shell structure of these samples was identified by dynamic light scattering (DLS) and high-resolution transmission electron microscope (HR-TEM). Moreover, HR-TEM images indicated that the core-shell structure of the microsphere does not undergo complete phase inversion. In addition, with increasing content of borneol acrylate in the shell, the water resistance and antibacterial adhesion of films were improved. The X-ray photoelectron spectroscopy (XPS), Energy Dispersive Spectrometer (EDS), water contact angle (CA) measurements, antibacterial and anti-adhesion tests demonstrate that the $\mathrm{C} / \mathrm{N}$ ratios of films from the inside to the upper surface had an obvious gradient in growth, indicating the shell component (polyborneol acrylate) was predominantly present at the surface of films after coalescence in cross-linked core-shell PUA. It was found that a suitable degree of cross-linking contributes to the segregation of the hydrophobic component (borneol groups) on the film surface. As a consequence, the excellent water resistance, cytocompatibility, and antibacterial properties endowed this series of polymer materials with promising application potential in the biomedical field.
\end{abstract}

Keywords: cross-linked; core-shell structure; antibacterial-adhesion coating; water resistance; cytocompatibility

\section{Introduction}

Bacterial infections are one of the most important risks for human health, which leads to significant mortality and morbidity worldwide [1,2]. The adherence of bacteria and subsequent formation of biofilms causes foreign bodies to become infected [3]. Thus, antibacterial coatings have become a 
focus of research during recent years. However, the antibacterial surface has both advantages and disadvantages. For instance, although the antibacterial surface can kill or prevent the initial adhesion of bacteria, this kind of surface is poor in biocompatibility, short-term antibacterial activity and easy degradation $[4,5]$. Furthermore, the use of antibacterial agents in the coating, such as antibiotics, is further limited due to the significant rise in antibiotic resistance [6].

The antibacterial-adhesion coating represents an attractive alternative to traditional antibacterial coatings, since it displays biocompatibility in various models and has broad-spectrum activity [7]. There are three main stages of development of bacterial adhesion: initial adhesion, multiplication to form colonies, and the formation of a biofilm. In stage of initial adhesion, the adhesive forces operating on bacteria are the Van der Waals force, electrostatic force, and hydrophilic and hydrophobic action. These forces are weak and the adhesion of bacteria to the surface is reversible, nonspecific and easily broken. After the adhesion of bacteria to the surface, the bacterial adhesion changes from reversible to irreversible and then the biofilm forms [8,9]. In response to this phenomenon, a large variety of surface types have been successfully developed to reduce the adhesion of bacteria during the initial adhesion phase, and these can consequently reduce the formation of biofilm. Hedrick et al. [10] prepared a series of polymers that were modified to introduce antimicrobial properties by improving hydrophobicity. Cui and Fan et al. [11] reported superhydrophobic coatings based on biodegradable polymers and modified silica microspheres, which could be conveniently fabricated through a co-electrospraying technique. The superhydrophobic film reduces the chance for cells or bacteria to firmly attach to the substrate because of the air trapped between the film and water [1,12-15].

Polymer surface stereochemistry is a practical and effective strategy to dramatically reduce bacterial attachment and biofilm formation due to interactions based on chiral stereochemistry [16]. Mitchell et al. [17] reported stereochemical-based knowledge could be used to improve the design of new antibacterial adhesion prophylactics. Inspired by the natural product, some researchers devoted attention to utilizing borneol to design a novel antibacterial adhesion polymer surface [18,19]. In addition, it is observed that borneol-based polymer is biocompatible and environmentally friendly, but the expensive price of monomers limits its effective application $[16,20,21]$. In general, core-shell microspheres composed of hydrophobic borneol components and hydrophilic components can solve this problem [22,23]. Because the microspheres with core-shell structure collapse to form films, the hydrophobic shell is enriched on the film surface due to surface tension. However, the moist environment and the chemical composition of core-shell microspheres can lead to the instability of self-migration or phase inversion [24-26].

With the above considerations in mind, the present work has been undertaken to synthesize hydrophobic borneol monomers which are then incorporated onto the shell layer of microspheres composed of methyl methacrylate (MMA) by means of a two-step polymerization technique. Cross-linked polyurethane (PU) core is selected because its cross-linking structure will limit the phase inversion of the core-shell structure and facilitate the migration of hydrophobic components to the film surface. In addition, it has good film-forming property and will not cause the cracking of membrane because of cross-linking. Therefore, this type of novel core-shell borneol-based PUA is of great potential to realize a convenient and effective strategy to prepare antibacterial adhesion films for antibacterial applications.

\section{Materials and methods}

\subsection{Materials}

Endo-L-Borneol, tetrahydrofuran (THF), triethylamine (TEA), acryloyl chloride, MMA, potassium peroxydisulfate and diethylenetriamine from Aladdin Chemistry Co., Ltd. (Shanghai, China) were used as received. Poly(propylene glycol) (PPG, Mw = 2000), isofordone diisocyanate (IPDI), 2,2-bis(hydroxymethyl)butyric acid (DMPA) and hydroxyethyl methacrylate (HEMA) from Sigma-Aldrich (St. Louis, MO, USA) were used as received. 


\subsection{Synthesis of Borneol Acrylate (BA) Monomer}

Endo-L-Borneol (1.00 g) and TEA (0.98 g) were dissolved in $20 \mathrm{~mL}$ of THF. Acryloyl chloride $(0.88 \mathrm{~g})$ was added drop-wise and then the reaction mixture was stirred at $30^{\circ} \mathrm{C}$ for $10 \mathrm{~h}$. The reaction mixture was filtered and evaporated to obtain the crude product which was brown oil. The conversion rate of the product reached $63 \%$. The ${ }^{1} \mathrm{H}$ NMR spectra of the BA and its detailed assignment of proton peaks is shown in Figure $\mathrm{S} 1$ (in the supporting information). ${ }^{1} \mathrm{H}$ NMR $\left(600 \mathrm{MHz}, \mathrm{CDCl}_{3}\right) 6.42$ $(\mathrm{t}, J=24 \mathrm{~Hz}, 1 \mathrm{H}), 6.18-6.09(\mathrm{~m}, 1 \mathrm{H}), 5.85(\mathrm{dd}, J=24,18 \mathrm{~Hz}, 1 \mathrm{H}), 5.03(\mathrm{~d}, J=24 \mathrm{~Hz}, 1 \mathrm{H}), 2.40-2.37(\mathrm{~m}$, $1 \mathrm{H}), 1.98-1.69(\mathrm{~m}, 6 \mathrm{H}), 1.35-1.23(\mathrm{~m}, 3 \mathrm{H}), 0.97(\mathrm{~d}, J=4.8 \mathrm{~Hz}, 3 \mathrm{H}), 0.87(\mathrm{t}, \mathrm{d}, J=4.8 \mathrm{~Hz}, 3 \mathrm{H})$ [20].

\subsection{Synthesis of PU Core Latex Particles}

The synthetic procedures for making PU core latex particles were based on a previous report [27-29]. Briefly, PPG-2000 (80 g) and IPDI ( $28 \mathrm{~g}$ ) were mixed in a three-necked round-bottom flask equipped with a thermometer, a mechanical stirrer and a refluxing condenser. After stirring for $5 \mathrm{~min}$ at room temperature, the system was heated to $110^{\circ} \mathrm{C}$. After $2 \mathrm{~h}$, DMPA $(5.5 \mathrm{~g})$ was added into the system and reacted for $4 \mathrm{~h}$. Then the system was cooled to $60^{\circ} \mathrm{C}$. $1 \mathrm{~g}$ HEMA and $30 \mathrm{~g}$ acetone were added and the temperature was maintained for $4 \mathrm{~h}$. After the system was cooled to $50{ }^{\circ} \mathrm{C}, 3.8 \mathrm{~g}$ TEA was added with stirring for $10 \mathrm{~min}$. Subsequently, $255 \mathrm{~g}$ deionized water was added and the reaction mixture was emulsified with vigorous stirring (1500 rpm). The emulsification was allowed to proceed for $5 \mathrm{~min}$, then the mixture of $5.7 \mathrm{~g}$ and $50 \mathrm{~g}$ deionized water was added drop-wise with moderating stirring. The cross-linking reaction was allowed to proceed for $1 \mathrm{~h}$. The conversion rate of each step of the reaction can be calculated by detecting the content of the unreacted NCO group through using dibutylamine back titration method because each step in previous three steps of the reaction involved NCO group. After testing, it was found that the conversion rate was $27.7 \%$ in the first step, $58.1 \%$ in the second step and $63.9 \%$ in the third step in Figure 1. In the fourth step, the degree of cross-linking was characterized with gel rate and the gel rate was $71.8 \%$.

\subsection{Preparation of the Core-shell Latex Particles}

To a $100 \mathrm{~mL}$ three-necked flask, $12 \mathrm{~g}$ PU core seed latex, prescribed amount of Endo-L-borneol acrylate, $2.5 \mathrm{~g}$ methyl methacrylate and $15 \mathrm{~g}$ water were added. The system was stirred at $300 \mathrm{r} / \mathrm{min}$ and nitrogen was bubbled through it for $2 \mathrm{~h}$. The polymerization was initiated by immersing the flask into the oil bath with the thermostat set at $80^{\circ} \mathrm{C}$. Meanwhile, the initiator ( $0.05 \mathrm{~g}$ KPS) dissolved in $10 \mathrm{~mL}$ water was slowly added drop-wise into the reactor. Lastly, the system was reacted for $8 \mathrm{~h}$. The conversion rate was $91.8 \%$ which was tested by weighing method.

\subsection{Film Preparation}

A polytetrafluoroethylene (PTFE) mold $(15 \mathrm{~cm} \times 15 \mathrm{~cm} \times 0.5 \mathrm{~cm})$ was cleaned in an ultrasonic cleaning bath with acetone at $50{ }^{\circ} \mathrm{C}$ for $1 \mathrm{~h}$ and rinsed with deionized water three times. Then the latexes were directly cast in the pre-cleaned PTFE mold. The resultant films were allowed to dry at room temperature for $24 \mathrm{~h}$ and were then thermally treated in an oven at $120^{\circ} \mathrm{C}$ for $48 \mathrm{~h}$.

\subsection{Characterization}

Dynamic light scattering (DLS) measurements of latexes were performed on a Malvern Zetasizer Nano-ZS90 instrument (Malvern, UK) at room temperature. The average particle size was calculated via the Stoke-Einstein equation.

HR-TEM were measured on a JEM-2000EX instrument. The latexes were diluted in deionized water to a ratio of 1 to 300 and stained with $6 \%$ phosphotungstic acid solution. Then the diluted suspension was coated on a copper grid for measurements.

Attenuated total reflection Fourier transform infrared (ATR-FTIR) spectra of the microspheres were performed on an EQUINOX55 FTIR spectrometer (Bruker, Rheinstetten, Germany) equipped 
with an ATR accessory, using an infrared beam fixed at an incident angle of $45^{\circ}$. The neat ATR element and wafer were measured as background spectra.

XPS analyses of the surfaces of latex films were performed on a Perkin Elmer ESCA 5600 spectrometer (Perkin Elmer, Shelton, CT, USA) with Mg K $\alpha$ X-ray source (1253.6 eV). Spectra were acquired at a take-off angle of $0^{\circ}$. The survey spectra from 0 to $1000 \mathrm{eV}$ were acquired.

The gel contents $(\mathrm{G})$ of the samples were measured to confirm the occurrence of cross-linking reaction. At first, the dried samples were weighed $\left(\mathrm{W}_{\mathrm{i}}\right)$. Then the samples were soaked and stirred in acetone for $36 \mathrm{~h}$ at room temperature. The samples were isolated and reweighed after drying at $80^{\circ} \mathrm{C}$ for $2 \mathrm{~h}\left(\mathrm{~W}_{\mathrm{f}}\right)$, the percentage of gel contents were calculated according to Equation (1) [23,24]:

$$
\mathrm{G}=\frac{\mathrm{W}_{\mathrm{f}}}{\mathrm{W}_{\mathrm{i}}} \times 100 \%
$$

CA of water was tested by a contact angle goniometer (Dataphysics, Germany) at room temperature. For each sample, two films were used for contact angle measurements; $4 \mu \mathrm{L}$ droplets were tested on three different places $100 \mathrm{~s}$ after depositing on the surface. The obtained values were averaged. Regarding deposition time of contact angle measurements, it was observed in preliminary experiments that most changes in drop roundness and contact angle values occurred during the initial $60 \mathrm{~s}$. On the other hand, longer deposition times are inconvenient, which may lead to significant evaporation and induce irregular drop shapes. Therefore, the deposition time was set at $100 \mathrm{~s}$ [30]. The experimental errors of the contact angles are within $\pm 2^{\circ}$.

Strains of the bacterium Escherichia coli (E. coli) were picked into a $50 \mathrm{~mL}$ sterile liquid medium, followed by overnight culturing at $37^{\circ} \mathrm{C}$ with a shaking rate of $200 \mathrm{rpm}$. Finally, the E. coli solutions were diluted to a concentration of $10^{7} \mathrm{CFU} \mathrm{mL} \mathrm{m}^{-1}$ (colony-forming units) with sterile phosphate-buffered saline (PBS) solution.

A "prison break" experiment $[16,21]$ was conducted to investigate interactions between bacteria and samples. The circular samples were fixed onto solid agar medium and sterilized under ultraviolet light. Then a small circular sterile agar block was fixed onto each sample, forming a special sandwich structure. After that, $5 \mu \mathrm{L}$ of $E$. coli suspension $\left(10^{7} \mathrm{CFU} \mathrm{mL}^{-1}\right)$ was added on each of the small circular agar block and cultured at $37^{\circ} \mathrm{C}$. The results were recorded after $24 \mathrm{~h}$ by a camera.

The plate count method [31,32] was employed to investigate the anti-adhesion capability of samples. Firstly, each sample was cultured in $10 \mathrm{~mL}$ of E. coli suspension $\left(10^{7} \mathrm{CFU} \mathrm{mL}{ }^{-1}\right)$ for $24 \mathrm{~h}$. Second, to remove the non-adherent bacteria, each sample was gently rinsed with sterile water more than three times. Then each sample was placed into a $5 \mathrm{~mL}$ solution of sterile PBS, followed by ultrasonication in an ultrasonic bath to remove the bacteria from the surface of sample. In the end, $100 \mu \mathrm{L}$ suspensions were coated on solid agar medium and then cultured for $24 \mathrm{~h}$ at $37^{\circ} \mathrm{C}$. The number of E. coli colonies was counted and each experiment was repeated at least three times.

Cytotoxicity of the film was examined by the in-vitro cytotoxicity-indirect cytotoxicity test. L929 mouse fibroblasts (ATCC NCTC clone 929:CCL 1) were cultivated with 10\% Fetal Bovine Serum in Dulbecco's modified Eagle's medium. Incubation conditions were $5 \% \mathrm{CO}_{2}$ and higher than $90 \%$ relative humidity atmosphere at $37^{\circ} \mathrm{C}$. The films were immersed in the medium and incubated for $72 \mathrm{~h}$. Then the films were interacted with L929 cells at $1 \times 10^{5}$ cells/mL densities in 96 well plates overnight. After $24 \mathrm{~h}$, the mediums were changed with 10\% 3-(4,5-dimethylthiazol-2-yl)-2,5-diphenyltetrazolium bromide (MTT) reagent and incubated at $37^{\circ} \mathrm{C}$ for $4 \mathrm{~h}$. The culture medium was removed and $100 \mu \mathrm{L}$ propan-2-ol solution (with $0.04 \mathrm{M} \mathrm{HCl}$ ) was added followed by incubation. The cell viability was tested using the MTT reduction assay and the absorbance was tested at $570 \mathrm{~nm}$ using a micro plate reader. 
$\mathrm{a}$

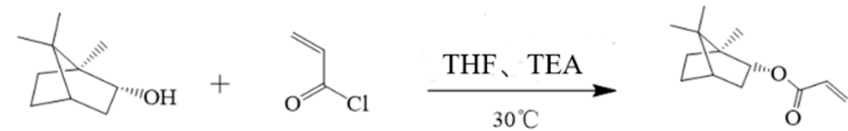

BA

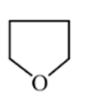

THF<smiles>CCC(CC)CC</smiles>

TEA

b
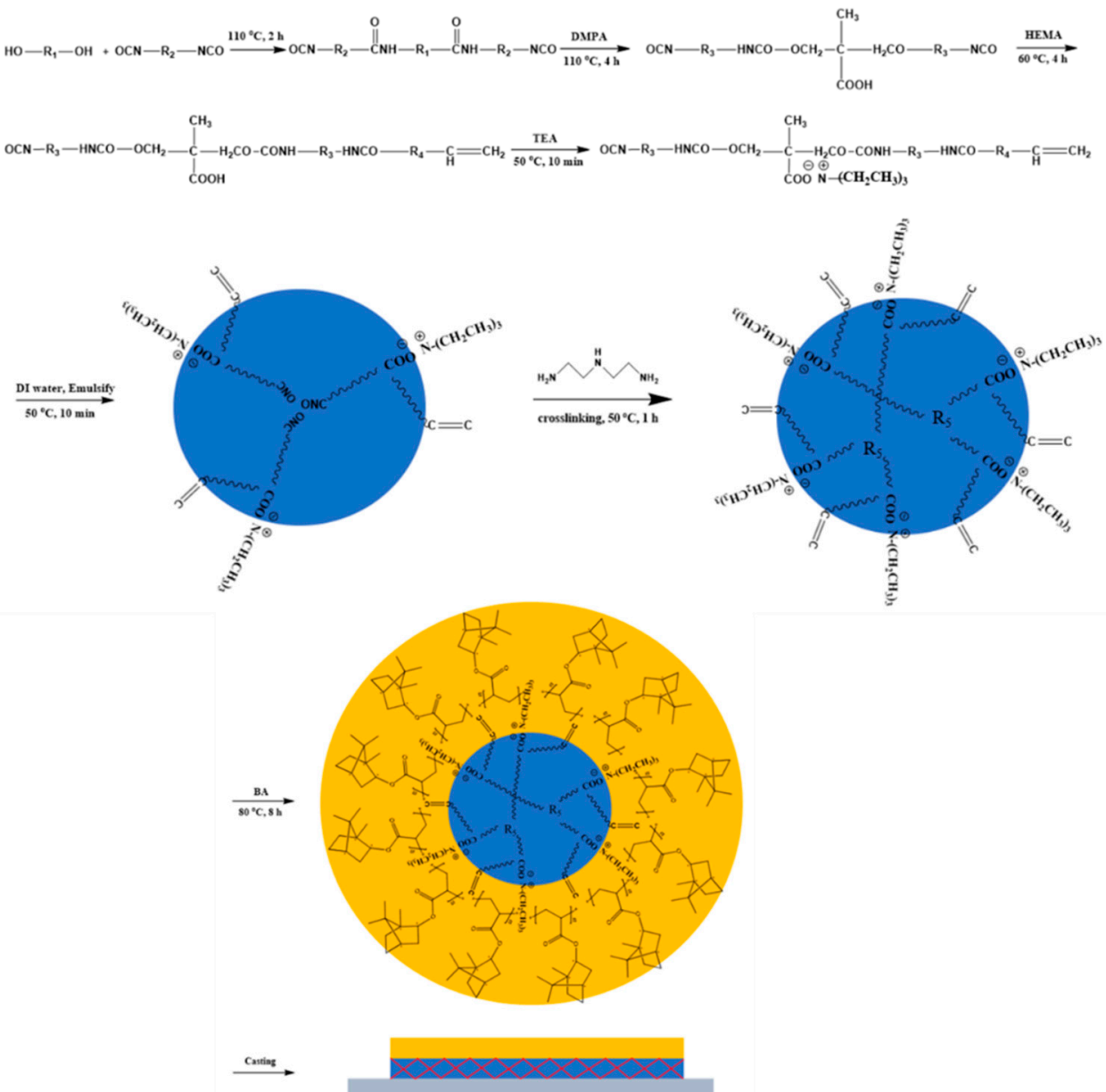

$\mathrm{N}_{\mathrm{n}}$

$\mathbf{R}_{2}$<smiles>CCC1(C)CC(C)CC(C)(C)C1</smiles><smiles>CNC(=O)CNC(=O)OC</smiles><smiles>CCOCCOC(C)=O</smiles>

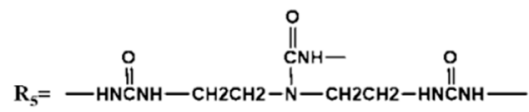
DMPA: $\begin{gathered}\mathrm{COH}_{2} \mathrm{C}-\mathrm{C}-\mathrm{CH}_{3} \mathrm{OH} \\ \stackrel{\mathrm{COOH}}{l}\end{gathered}$<smiles>CC(C)=CC(=O)OCO</smiles>
MMA:<smiles>C=C(C)C(=O)OC</smiles>

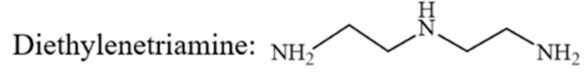

Figure 1. Schematic diagram of the fabrication process for (a) BA monomer and (b) Endo-L-Borneol based PUA film.

\section{Results and Discussion}

As illustrated in Figure 1, the cross-linked PU core containing vinyl groups-based PPG, IPDI and cross-linked diethylenetriamine was synthesized first. Subsequently, the mixture of Endo-L-Borneol acrylate and MMA was further copolymerized at the surface of PU core to produce the cross-linked core-shell PUA microsphere. Lastly, the latexes were directly cast in the pre-cleaned PTFE molds to 
produce Endo-L-Borneol PUA based films. In order to study the effect of core-shell structure of latex microspheres and content of Endo-L-Borneol acrylate on the property of latex films, the percentage of Endo-L-Borneol acrylate monomers in the copolymers was adjusted in the range from $0 \mathrm{wt} . \%$ to $54 \mathrm{wt} . \%$.

The size distributions of PU particles and core-shell particles obtained were measured using the DLS method. The DLS curves for core and core-shell particles prepared with $0 \mathrm{wt} . \%, 23 \mathrm{wt} . \%$, $37 \mathrm{wt} . \%$ and $54 \mathrm{wt.} \%$ Endo-L-Borneol acrylate, respectively, are presented in Figure 2. As can be seen, relative to the core particles, the curves of particles obtained in the second stage obviously shift towards the right. The DLS measurements indicate that a new layer has formed and coated the core surface to form a core-shell structure. The z-average diameter of PU core is $52.3 \mathrm{~nm}$, while the z-average diameters of the core-shell particles are $75.6 \mathrm{~nm}, 83.2 \mathrm{~nm}$ and $108.9 \mathrm{~nm}$, respectively. In addition, the core-shell structures of the Endo-L-Borneol acrylate based PUA microspheres were further confirmed by HR-TEM (Figure 3) and FTIR spectra (Figure 4). It is seen that the particles are spherical and uniform. The latex particles exhibit quite clear core-shell interfaces. The black core layer is the PU layer because the electron cloud is denser and the brighter shell layer is the acrylate layer containing borneol group $[27,33]$. Due to the effect of surface tension, the hydrophilic PU components often turn into the shell when the microspheres of PU core/polyacrylate shell are in the aqueous phase. It indicates that the cross-linked structures cause the core-shell microspheres not to undergo a phase inversion process. The gel contents of the samples were measured by swelling experiments in acetone to confirm the occurrence of cross-linking reaction. By calculation, the gel content of the cross-linked PU core is $71.8 \%$. This demonstrates that the formation of cross-linked polymer networks in PU core, which supports the occurrence of cross-linking reaction. After being coated with polyacrylate shell, the FTIR spectra of PUA particles show apparent increase of $C=O$ stretching vibration at $1725 \mathrm{~cm}^{-1}$ and decrease of $\mathrm{C}-\mathrm{N}$ stretching and $\mathrm{N}-\mathrm{H}$ bending at $1526 \mathrm{~cm}^{-1}$, compared to that of the PU core. These results verify the presence of polyacrylate on the PU core.

The Endo-L-Borneol acrylate based PUA emulsion was directly cast into a PTFE mold to prepare latex films whose weight ratios of Endo-L-Borneol acrylate to total weight were $0 \mathrm{wt} . \%, 23 \mathrm{wt} . \%$, $37 \mathrm{wt} . \%$ and $54 \mathrm{wt} . \%$. Then the films were removed from PTFE mold. The chemical compositions of upper and inside surface of films were studied by EDS.

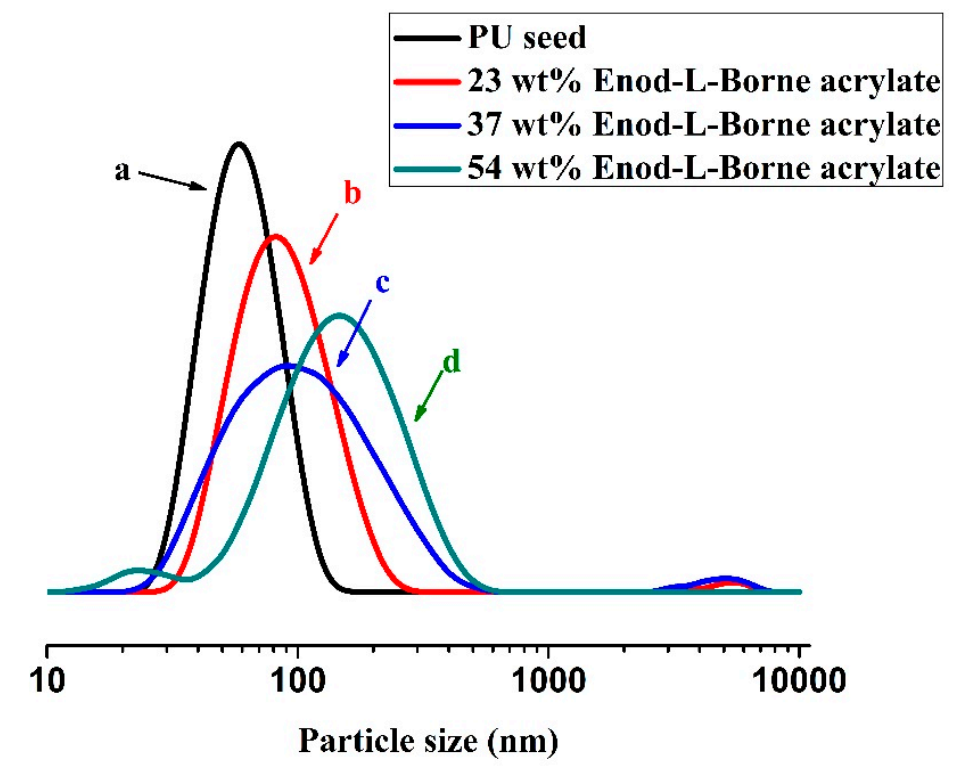

Figure 2. Size distribution curves of the core and core-shell latex particles: (a) PU seed; (b) 23 wt.\% Endo-L-Borneol acrylate; (c) 37 wt.\% Endo-L-Borneol acrylate; (d) 54 wt.\% Endo-L-Borneol acrylate. 


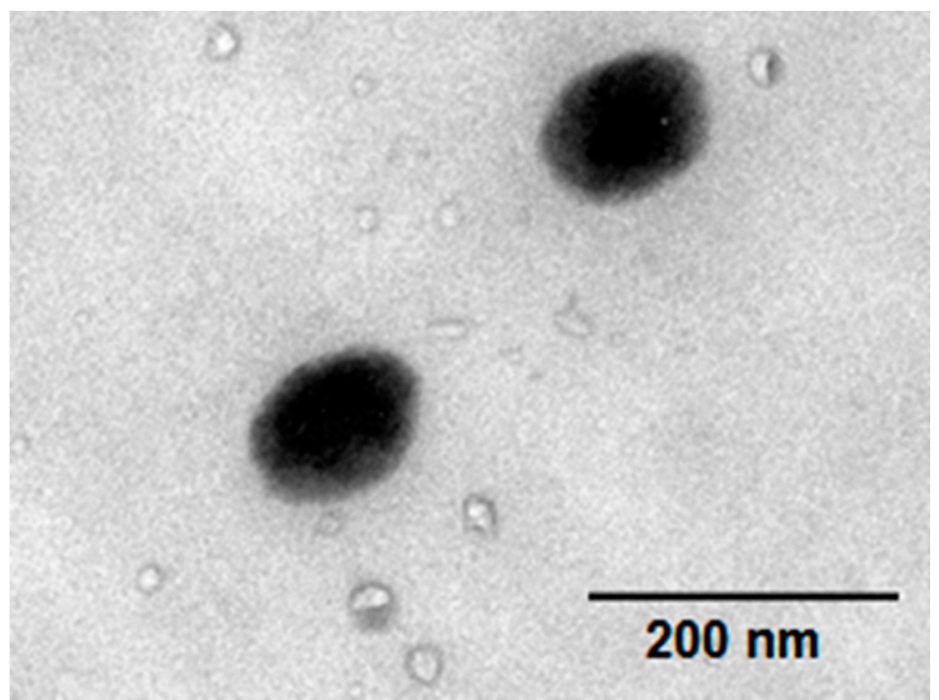

Figure 3. HR-TEM images of core-shell-structured latex particles.

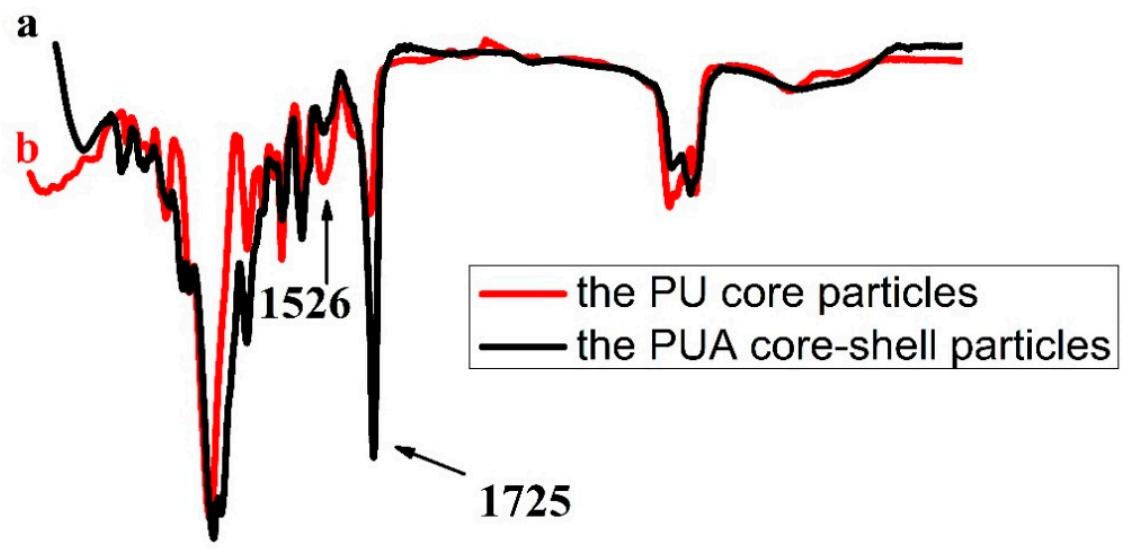

\section{0 \\ Wavenumber $\left(\mathrm{cm}^{-1}\right)$}

Figure 4. FTIR spectra of (a) the PUA core-shell particles and (b) the PU core particles.

Taking the film (37 wt.\% Endo-L-Borneol acrylate) as an example, the EDS spectra of the upper and inside surface of film display the signals of $\mathrm{C}, \mathrm{O}$ and N, as shown in Figure 5. Compared to the upper surface of film, the inside surface of film has a larger amount of $\mathrm{O}$ and $\mathrm{N}$. The same results can be observed in mapping images. In addition, the mapping images show that the elements of $\mathrm{O}$ and $\mathrm{N}$ homogeneously distribute in the films. The reason may be that PUA core-shell latex particles tend to enrich on the shell layer when the films form. In this study, PUA shell contains a hydrophobic Endo-L-Borneol group, and the core contains a hydrophilic carboxyl group and these two polymer chain segments have different surface tensions. Therefore, when the microsphere collapses, the chain segments with different surface tensions have higher migration ability, resulting in more obvious phase separation of the film. 
(a)

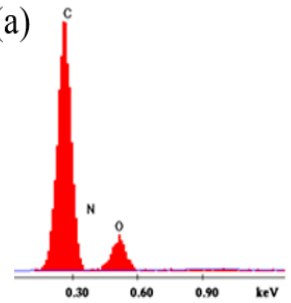

(b)

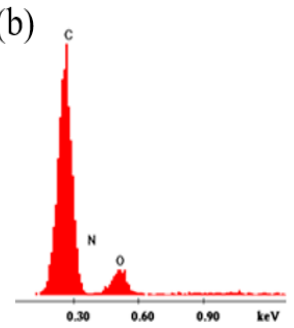

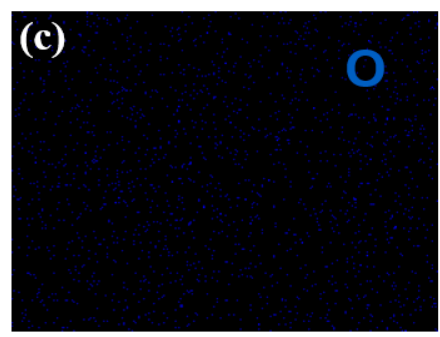
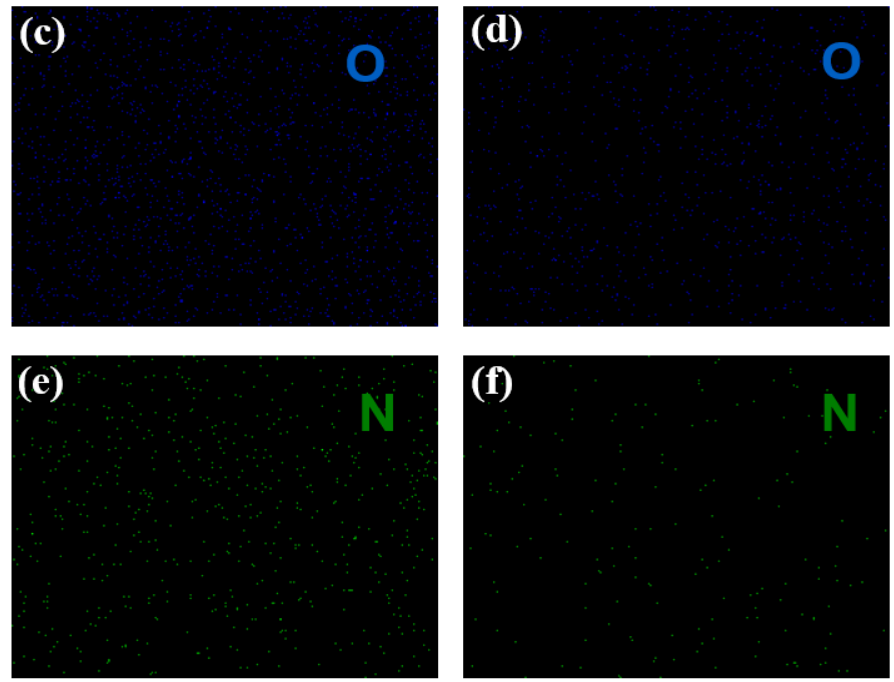

(f)

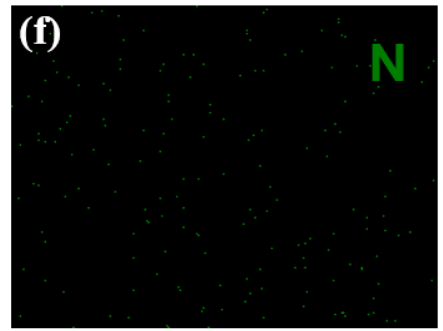

Figure 5. The EDS spectra and mapping images of the PUA latex films (37 wt.\% Endo-L-Borneol acrylate). (a) The EDS spectrum of the inside surface of film. (b) The EDS spectrum of the upper surface. (c) The mapping image of the element $\mathrm{O}$ in the inside surface. (d) The mapping image of the element $\mathrm{O}$ of upper surface. (e) The mapping image of element $\mathrm{N}$ in the inside surface. (f) The mapping image of element $\mathrm{N}$ of the upper surface.

Due to the phase separation of the film, the hydrophobicity of upper surface differs that of inside surface. Thus, contact angle (CA) measurements were applied to check the surface wettability of upper and inside surfaces of three different films, and the larger static CA values indicate better hydrophobicity [34]. As shown in Figure 6, the static water CA values of upper and inside surfaces of three films (23 wt.\%, $37 \mathrm{wt} . \%$ and $54 \mathrm{wt} . \%$ Endo-L-Borneol acrylate) range from $62.8^{\circ}$ to $90.3^{\circ}$. Taking the film (23 wt.\% Endo-L-Borneol acrylate) as an example, the upper surface has a static water CA value of $75.0^{\circ}$, while the inside surface displays a lower static water CA value of $62.8^{\circ}$. The same results can also be observed in other two films. This phenomenon can be attributed to the phase separation of the film which can be illustrated by the surface tension. And CA measurements can be used to calculate the surface tension at different positions of the film. The water contact angles were used to calculate the solid surface tension $\left(\gamma_{\mathrm{sv}}\right)$ using the equation of state approach $[23,25]$ :

$$
1+\cos \theta=2 \sqrt{\frac{\gamma_{\mathrm{SV}}}{\gamma_{\mathrm{lV}}}} \mathrm{e}^{-\beta\left(\gamma_{\mathrm{lV}}-\gamma_{\mathrm{sV}}\right)^{2}}
$$

where $\beta$ is an empirical parameter and is found to be $0.0001247(\mathrm{mN} / \mathrm{m})^{-2}$, while $\gamma_{\mathrm{sv}}$ and $\gamma_{\mathrm{lv}}$ denote the interfacial tensions of solid-air and liquid-air interfaces, respectively. $\theta$ is the contact angle of liquid. From the static water contact angles of the upper and inside surface of film (23 wt.\% Endo-L-Borneol acrylate), the calculated surface tension of upper surface according to Equation (1) is $38.61 \mathrm{mN} / \mathrm{m}$, while the surface tension of inside surface is $39.99 \mathrm{mN} / \mathrm{m}$ which is slightly higher than that of the upper surface. The same phenomenon can also be observed in the other two films. These results prove that the phase separation has taken place in the films.

This conclusion was further demonstrated by XPS spectra in Figure 7. It is observed that the peaks at 284, 532 and $401 \mathrm{eV}$ correspond to $\mathrm{C} 1 \mathrm{~s}, \mathrm{O}$ 1s and $\mathrm{N} 1 \mathrm{~s}$. The experimental values of elemental concentration percentages of $\mathrm{C}, \mathrm{N}$ and $\mathrm{O}$ elements in the upper surface of $37 \mathrm{wt}$ \% Endo-L-Borneol acrylate is $78.63 \%, 1.18 \%$ and $20.19 \%$ and that of the inside surface is $68.19 \%, 2.71 \%$ and $29.10 \%$. The elemental concentration percentages of $\mathrm{C}, \mathrm{N}$ and $\mathrm{O}$ elements on upper surface of 54 wt.\% Endo-L-Borneol acrylate is $82.82 \%, 1.06 \%$ and $16.13 \%$ and that on inside surface is $73.48 \%, 2.14 \%$ and $24.38 \%$. These data indicate that the contents of $\mathrm{O}$ and $\mathrm{N}$ of the inside surface of film (37 wt. $\%$ Endo-L-Borneol acrylate) are higher than those of the upper surface as indicating phase separation 
of film. The XPS survey spectra and high resolution C1s spectra for the upper and inside surface of film are shown in Figure 7. The signals of $\mathrm{C}-\mathrm{O}$ locate at binding energy of $286.3 \mathrm{eV}$ and the peak at $289.1 \mathrm{eV}$ shows the presence of $\mathrm{COO}+\mathrm{NH}-\mathrm{C}(=\mathrm{O})-\mathrm{O}$. The signal at $284.7 \mathrm{eV}$ is corresponded to the other aliphatic and cycloaliphatic carbons $[35,36]$.

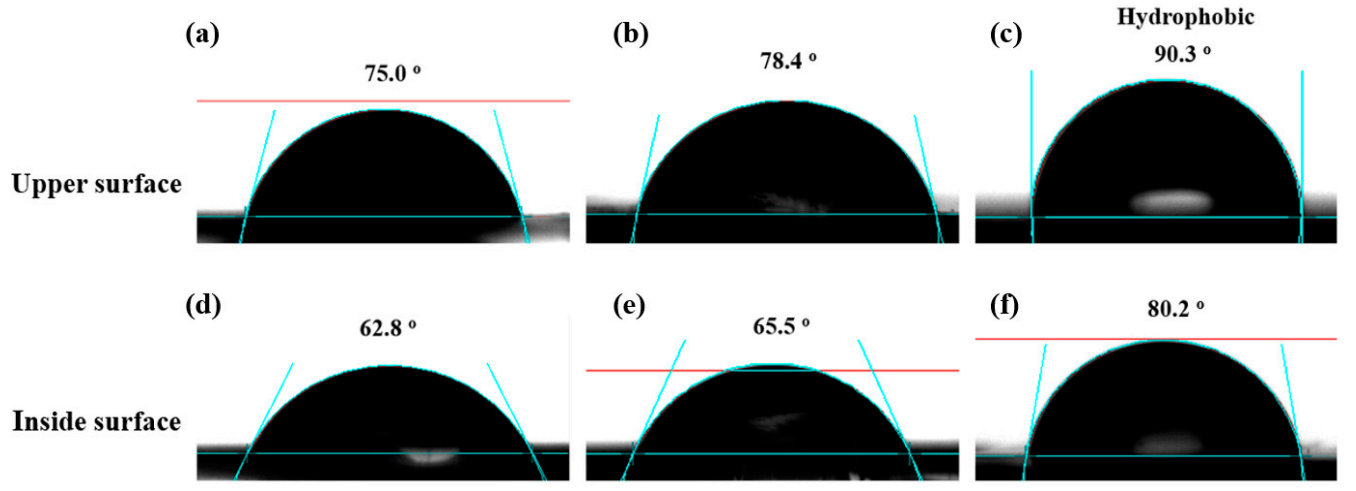

Figure 6. The static water CA measurements on upper and inside surfaces of three films: (a) upper surfaces of $23 \mathrm{wt}$ \% Endo-L-Borneol acrylate; (b) upper surfaces of $37 \mathrm{wt} \%$ Endo-L-Borneol acrylate; (c) upper surfaces of 54 wt.\% Endo-L-Borneol acrylate; (d) inside surfaces of $23 \mathrm{wt} . \%$ Endo-L-Borneol acrylate; (e) inside surfaces of 37 wt.\% Endo-L-Borneol acrylate; (f) inside surfaces of 54 wt.\% Endo-L-Borneol acrylate.
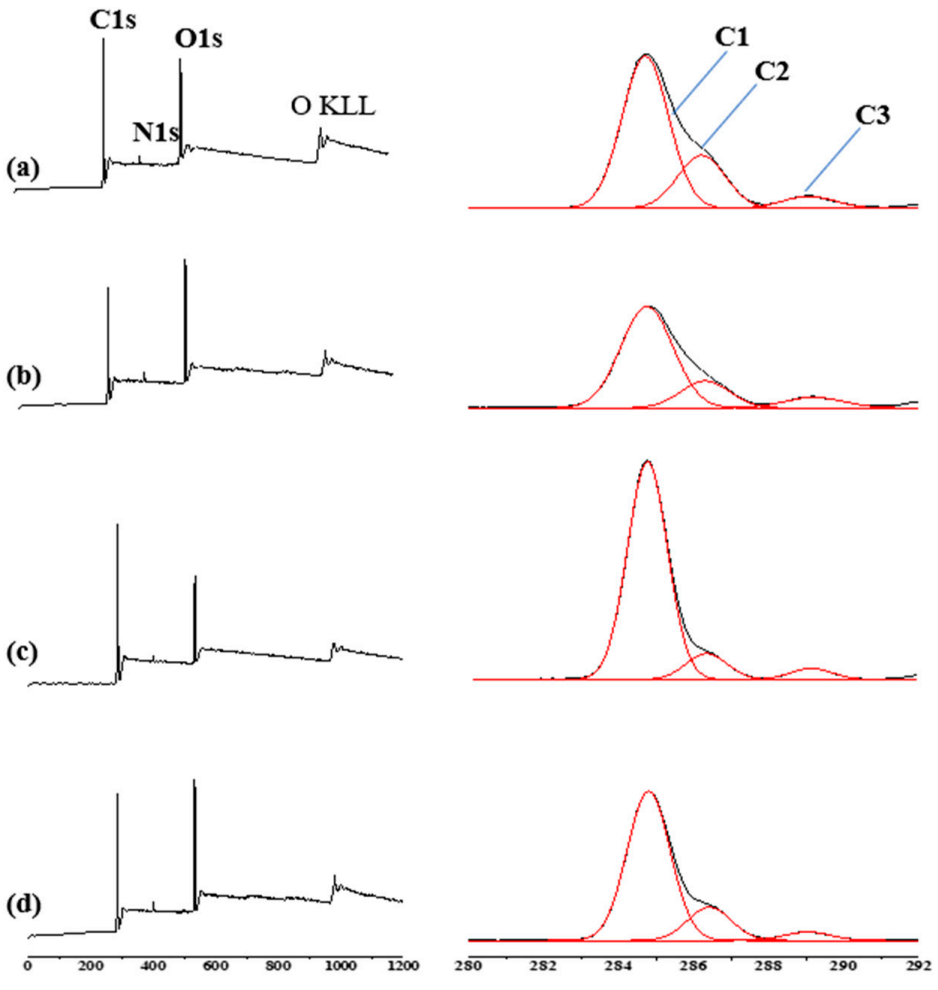

Binding Energy (eV)

Figure 7. XPS spectra images of the PUA latex films and fine spectra fitting, $\mathrm{C} 3(\mathrm{COO}+\mathrm{NH}-\mathrm{C}(=\mathrm{O})-\mathrm{O})$, $\mathrm{C} 2(\mathrm{C}-\mathrm{O})$ and $\mathrm{C} 1$ (aliphatic and cycloaliphatic carbons). (a) upper surface of the film (37 wt.\% Endo-L-Borneol acrylate) with $\mathrm{C} 1 / \mathrm{C} 3$ atomic ratio of 11.2; (b) inside surface of the film (37 wt.\% Endo-L-Borneol acrylate) with $\mathrm{C} 1 / \mathrm{C} 3$ atomic ratio of 8.3 , (c) upper surface of the film (54 wt.\% Endo-L-Borneol acrylate) with C1/C3 atomic ratio of 18.2, (d) inside surface of the film (54 wt.\% Endo-L-Borneol acrylate) with $\mathrm{C} 1 / \mathrm{C} 3$ atomic ratio of 16.5 . 
$\mathrm{C} 3$ is the $\mathrm{COO}+\mathrm{NH}-\mathrm{C}(=\mathrm{O})-\mathrm{O}, \mathrm{C} 2$ is $\mathrm{C}-\mathrm{O}$ and $\mathrm{C} 1$ is aliphatic and cycloaliphatic carbons, as is shown in Figure 7. The $\mathrm{C} 1 / \mathrm{C} 3$ atomic ratios as functions of the upper and inside surfaces of films which have different contents of Endo-L-Borneol acrylate (37 wt.\% and $54 \mathrm{wt} . \%$ ) is 11.2, 8.3, 18.2 and 16.5. The relative proportion of groups was computed from the areas under these curves in C1s. The ratio of $\mathrm{C} 1 / \mathrm{C} 3$ atoms on the upper surface of film is higher than that on the inside surface. The $\mathrm{COO}$ and $\mathrm{NH}-\mathrm{C}(=\mathrm{O})-\mathrm{O}) / \mathrm{C}-\mathrm{O}$ groups belong to the $\mathrm{PU}$ core, and the $\mathrm{C}=\mathrm{O}$ belongs to the $\mathrm{PU}$ core and polyacrylate shell. Because the ratio of $\mathrm{C}=\mathrm{O}$ group and $(\mathrm{COO}+\mathrm{NH}-\mathrm{C}(=\mathrm{O})-\mathrm{O}) / \mathrm{C}-\mathrm{O})$ group is fixed on PU core layer, the results in Figure 7 show that more polyacrylate components are enriched on the upper surface, while more PU components are enriched on the inside surface of film. These results are consistent with EDS analysis. In addition, with higher content of Endo-L-Borneol acrylate, this ratio is higher.

To evaluate the effect of anti-adhesion properties, a method called the "prison break" experiment was employed to demonstrate the capacity of films and inhibit the diffusion of Gram-negative E. coli (Figure 8). After $24 \mathrm{~h}$, E. coli successfully broke the restrictions of film in the control group to diffuse outside obviously. And neither the upper nor inside surface of film (23 wt.\% Endo-L-Borneol acrylate) can completely restrict the outward spread of E. coli. The upper surface of film (37 wt.\% Endo-L-Borneol acrylate) exhibits excellent restriction for the spreading out of $E$. coli, while the inside surface cannot efficiently inhibit the outward spread of E. coli. Meanwhile, both the upper and inside surface of film (54 wt.\% Endo-L-Borneol acrylate) display excellent anti-adhesion performance to inhibit the diffusion of E. coli, which cannot break the 'film prison'.

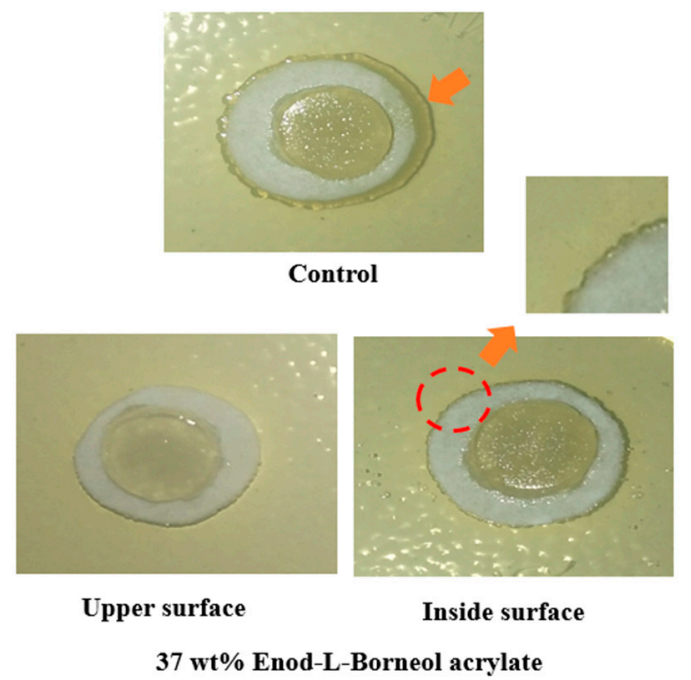

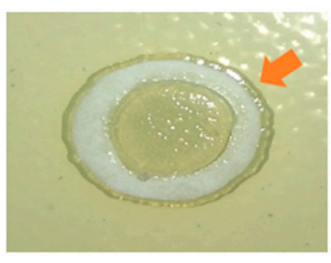

Upper surface

23 wt \% Enod-L-Borneol acrylate

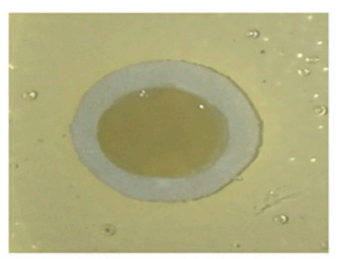

Upper surface

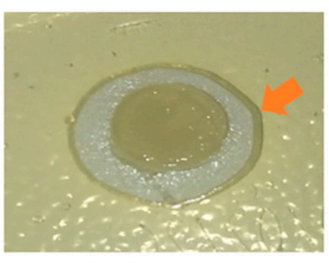

Inside surface

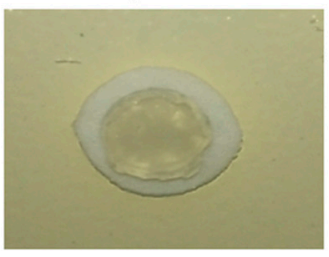

Inside surface

54 wt \% Enod-L-Borneol acrylate

Figure 8. Photographs of modified 'prison break' experiments for antibacterial adhesion assays of the films.

Anti-adhesion capacities of all films were also investigated by classical methods. Figure 9 illustrates the plate count results of the films. The colony numbers of E. coli on the upper and inside surfaces of films (23 wt. $\%, 37 \mathrm{wt} . \%$ and $54 \mathrm{wt.} \%$ Endo-L-Borneol acrylate) are $1.3 \times 10^{6}, 7.5 \times 10^{6}$, $8.6 \times 10^{5}, 1.6 \times 10^{6}, 0$ and 0 units, respectively. Taking the film ( $23 \mathrm{wt} . \%$ Endo-L-Borneol acrylate) as an example, the number of bacteria adhering to the upper surface was reduced by $82.6 \%$. It also suggests that the upper surface has better anti-adhesion performance compared with the inside surface. The phenomenon indicates that increasing content of Endo-L-Borneol acrylate leads to a gradually higher anti-adhesion effect. The upper surface has better anti-adhesion ability than the inside surface, which further confirms the existence of phase separation in films. Endo-L-Borneol acrylate migrates onto the upper surface, while PU is firmly fastened on the inside surface on account of the cross-linked structure. Because the content of Endo-L-Borneol acrylate in film (54 wt.\% Endo-L-Borneol acrylate) is high and the inside surface also has Endo-L-Borneol acrylate, the inside surface has a good anti-adhesion capacity. 


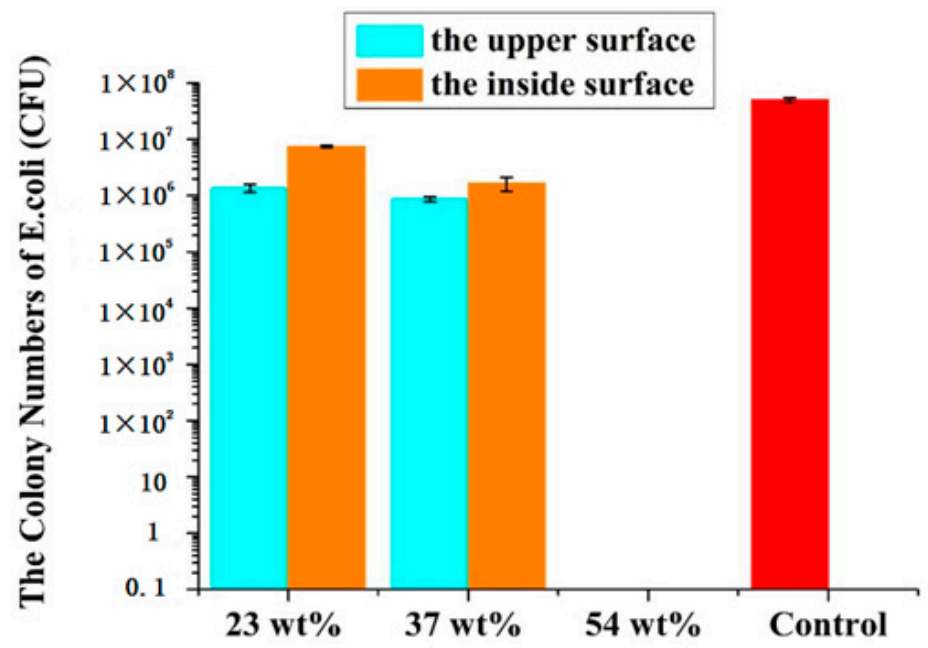

Figure 9. Anti-adhesion experiment: E. coli. colony numbers corresponding to E. coli on the films.

In order to demonstrate the cell toxicity of films, a tetrazolium-dye-based assay was employed. The results are displayed in Figure 10. PU was set as control group and the cell viability of PU reached nearly $100 \%$. The cell viability of the inside surfaces of the three films (23 wt. $\%, 37 \mathrm{wt} . \%$ and $54 \mathrm{wt} . \%$ Endo-L-Borneol acrylate) were above $95 \%$, indicating excellent cytocompatibility. The cell viability of the upper surfaces of three films (23 wt.\%, $37 \mathrm{wt} . \%$ and $54 \mathrm{wt} . \%$ Endo-L-Borneol acrylate) were $96 \%$, $94 \%$ and $92 \%$, respectively. With increasing amounts of Endo-L-Borneol acrylate, the cell viability of the inside surface decreases slightly and that of the upper surface decreases more obviously than the inside surface. Therefore, this material has a promising potential for applications in the biomedical field due to its cytocompatibility.

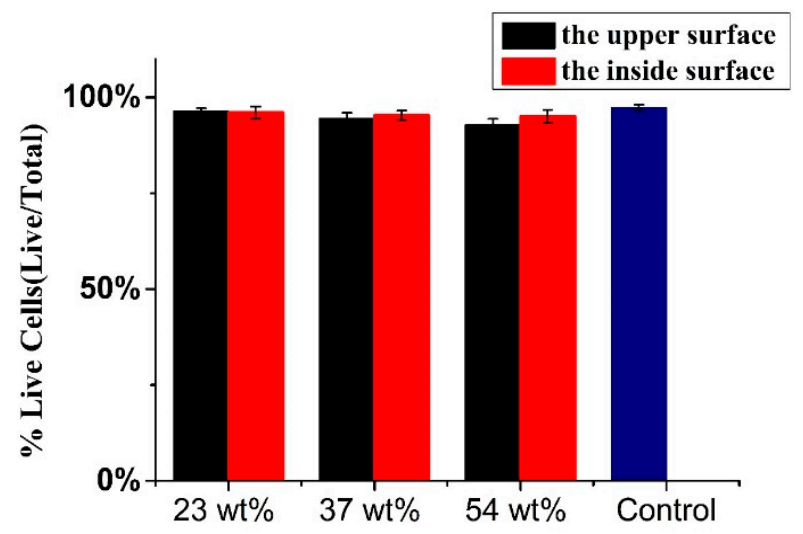

Figure 10. The in-vitro cytotoxicity tests of films.

\section{Conclusions}

In conclusion, high-quality cross-linked polyurethane/polymethyl methacrylate-borneol acrylate with adjustable shell thickness was prepared with PU seed particles as a core by controllable coating technology. The structures of these samples were characterized by DLS and HR-TEM. The results demonstrate that the samples have core-shell structures which are not completely reversed. With increasing content of borneol acrylate in shell, the hydrophobicity and antibacterial adhesion of films are improved. In addition, the ratio of $\mathrm{C} / \mathrm{N}$ increases in a gradient from the inside surface to the upper surface of film with increasing content of Endo-L-Borneol acrylate. The results show that proper cross-linking is beneficial to the separation of hydrophobic borneol from the surface of film, which makes the film have excellent antibacterial adhesion. Furthermore, the film has good cellular compatibility, which endows it with a excellent prospects for future applications in the biomedical field. 
Supplementary Materials: The following are available online at http://www.mdpi.com/2079-6412/10/1/65/s1, Figure S1: The ${ }^{1} \mathrm{H}$ NMR spectra of the BA.

Author Contributions: Data curation, L.W., Z.W. and Z.C.; formal analysis, Z.W. and Z.C.; funding acquisition, Z.W.; investigation, X.C., X.Y. and Y.B.; methodology, X.C., X.Y., L.L. and Y.Q.; project administration, Z.W.; writing-original draft, X.C. and X.Y.; Writing-review \& editing, Z.W. and Z.C. All authors have read and agree to the published version of the manuscript.

Funding: This work was financially supported by the General Research Projects of Zhejiang Provincial Department of Education (No. Y201840153).

Conflicts of Interest: The authors declare no competing financial interest.

\section{References}

1. Hwang, G.B.; Patir, A.; Allan, E.; Nair, S.P.; Parkin, I.P. Superhydrophobic and White Light-Activated Bactericidal Surface through a Simple Coating. ACS Appl. Mater. Interfaces 2017, 9, 29002-29009. [CrossRef]

2. Mahapatra, A.; Padhi, N.; Mahapatra, D.; Bhatt, M.; Sahoo, D.; Jena, S.; Dash, D.; Chayani, N. Study of biofilm in bacteria from water pipelines. J. Clin. Diagn. Res. 2015, 9, DC09. [CrossRef]

3. Hoiby, N.; Bjarnsholt, T.; Givskov, M.; Molin, S.; Ciofu, O. Antibiotic resistance of bacterial biofilms. Int. J. Antimicrob. Agents 2010, 35, 322-332. [CrossRef] [PubMed]

4. Jo, J.K.; El-Fiqi, A.; Lee, J.H.; Kim, D.A.; Kim, H.W.; Lee, H.H. Rechargeable microbial anti-adhesive polymethyl methacrylate incorporating silver sulfadiazine-loaded mesoporous silica nanocarriers. Dent. Mater. 2017, 33, 361-372. [CrossRef] [PubMed]

5. Hasan, J.; Crawford, R.J.; Ivanova, E.P. Antibacterial surfaces: The quest for a new generation of biomaterials. Trends Biotechnol. 2013, 31, 295-304. [CrossRef] [PubMed]

6. Zhao, L.; Wang, H.; Huo, K.; Cui, L.; Zhang, W.; Ni, H.; Zhang, Y.; Wu, Z.; Chu, P.K. Antibacterial nano-structured titania coating incorporated with silver nanoparticles. Biomaterials 2011, 32, 5706-5716. [CrossRef]

7. Yang, C.; Ding, X.; Ono, R.J.; Lee, H.; Hsu, L.Y.; Tong, Y.W.; Hedrick, J.; Yang, Y.Y. Brush-like polycarbonates containing dopamine, cations, and PEG providing a broad-spectrum, antibacterial, and antifouling surface via one-step coating. Adv. Mater. 2014, 26, 7346-7351. [CrossRef]

8. Fu, J.; Ji, J.; Yuan, W.; Shen, J. Construction of anti-adhesive and antibacterial multilayer films via layer-by-layer assembly of heparin and chitosan. Biomaterials 2005, 26, 6684-6692. [CrossRef]

9. Cloutier, M.; Mantovani, D.; Rosei, F. Antibacterial Coatings: Challenges, Perspectives, and Opportunities. Trends Biotechnol. 2015, 33, 637-652. [CrossRef]

10. Liu, S.Q.; Yang, C.; Huang, Y.; Ding, X.; Li, Y.; Fan, W.M.; Hedrick, J.L.; Yang, Y.Y. Antimicrobial and antifouling hydrogels formed in situ from polycarbonate and poly(ethylene glycol) via Michael addition. Adv. Mater. 2012, 24, 6484-6489. [CrossRef]

11. Hu, C.; Liu, S.; Li, B.; Yang, H.; Fan, C.; Cui, W. Micro-/nanometer rough structure of a superhydrophobic biodegradable coating by electrospraying for initial anti-bioadhesion. Adv. Healthc. Mater. 2013, 2, 1314-1321. [CrossRef] [PubMed]

12. Liu, H.; Wang, L.; Wang, M.; Hou, C.-J.; Ye B-b Wang, Z.; Bian, J. Engineered Multifunctional Fluorinated Film Based on Semicontinuous Emulsion Polymerization Using Polymerizable Quaternary Ammonium Emulsifiers. Int. J. Polym. Sci. 2018, 2018, 1-9. [CrossRef]

13. Shateri Khalil-Abad, M.; Yazdanshenas, M.E. Superhydrophobic antibacterial cotton textiles. J. Colloid Interface Sci. 2010, 351, 293-298. [CrossRef] [PubMed]

14. Wang, Z.; Ye, W.; Luo, X.; Wang, Z. Heat-Resistant Crack-Free Superhydrophobic Polydivinylbenzene Colloidal Films. Langmuir 2016, 32, 3079-3084. [CrossRef] [PubMed]

15. Wang, Z.; Ye, W.; Luo, X.; Wang, Z. Fabrication of Superhydrophobic and Luminescent Rare Earth/Polymer complex Films. Sci. Rep. 2016, 6, 24682. [CrossRef]

16. Sun, X.; Qian, Z.; Luo, L.; Yuan, Q.; Guo, X.; Tao, L.; Wei, Y.; Wang, X. Antibacterial Adhesion of Poly(methyl methacrylate) Modified by Borneol Acrylate. ACS Appl. Mater. Interfaces 2016, 8, 28522-28528. [CrossRef]

17. Mitchell, E.; Houles, C.; Sudakevitz, D.; Wimmerova, M.; Gautier, C.; Perez, S.; Wu, A.M.; Gilboa-Garber, N.; Imberty, A. Structural basis for oligosaccharide-mediated adhesion of Pseudomonas aeruginosa in the lungs of cystic fibrosis patients. Nat. Struct. Biol. 2002, 9, 918-921. [CrossRef] 
18. Mai, L.-M.; Lin, C.-Y.; Chen, C.-Y.; Tsai, Y.-C. Synergistic effect of bismuth subgallate and borneol, the major components of Sulbogin ${ }^{\circledR}$, on the healing of skin wound. Biomaterials 2003, 24, 3005-3012. [CrossRef]

19. He, M.; Jiang, H.; Wang, R.; Xie, Y.; Zhao, W.; Zhao, C. A versatile approach towards multi-functional surfaces via covalently attaching hydrogel thin layers. J. Colloid Interface Sci. 2016, 484, 60-69. [CrossRef]

20. Wang, X.; Jing, S.; Liu, Y.; Liu, S.; Tan, Y. Diblock copolymer containing bioinspired borneol and dopamine moieties: Synthesis and antibacterial coating applications. Polymer 2017, 116, 314-323. [CrossRef]

21. Luo, L.; Li, G.; Luan, D.; Yuan, Q.; Wei, Y.; Wang, X. Antibacterial adhesion of borneol-based polymer via surface chiral stereochemistry. ACS Appl. Mater. Interfaces 2014, 6, 19371-19377. [CrossRef] [PubMed]

22. Cui, X.; Zhong, S.; Wang, H. Emulsifier-free core-shell polyacrylate latex nanoparticles containing fluorine and silicon in shell. Polymer 2007, 48, 7241-7248. [CrossRef]

23. Wang, Z.; Wang, Z. Synthesis of cross-linkable fluorinated core-shell latex nanoparticles and the hydrophobic stability of films. Polymer 2015, 74, 216-223. [CrossRef]

24. Chai, S.L.; Jin, M.M.; Tan, H.M. Comparative study between core-shell and interpenetrating network structure polyurethane/polyacrylate composite emulsions. Eur. Polym. J. 2008, 44, 3306-3313. [CrossRef]

25. Yuan, C.; Wang, J.; Cui, M.; Peng, Y. Aqueous PUA emulsion prepared by dispersing polyurethane prepolymer in polyacrylate emulsion. J. Appl. Polym. Sci. 2016, 133, 43203. [CrossRef]

26. Otts, D.B.; Cueva-Parra, L.A.; Pandey, R.B.; Urban, M.W. Film Formation from Aqueous Polyurethane Dispersions of Reactive Hydrophobic and Hydrophilic Components; Spectroscopic Studies and Monte Carlo Simulations. Langmuir 2005, 21, 4034-4042. [CrossRef] [PubMed]

27. Zhao, M.; Li, H.; Wen, L.; Yu, Z.; Zhang, S.; Han, Z. Synthesis and characterization of fluorine-containing polyurethane-acrylate core-shell emulsion. J. Appl. Polym. Sci. 2016, 43357. [CrossRef]

28. Liu, J.; Wang, B.; Yuan, Y.; Liu, R.; Li, Z.; Liu, X. Synthesis of fluorinated polycarbonate-based polyurethane acrylate for UV-curable coatings. J. Coat. Technol. Res. 2017, 14, 233-241. [CrossRef]

29. Luo, Q.; Shen, Y.; Li, P.; Wang, C.; Zhao, Z. Synthesis and Characterization of Crosslinking Waterborne Fluorinated Polyurethane-Acrylate with Core-Shell Structure. J. Appl. Polym. Sci. 2014, 40970. [CrossRef]

30. Meiron, T.S.; Marmur, A.; Saguy, I.S. Contact angle measurement on rough surfaces. J. Colloid Interface Sci. 2004, 274, 637-644. [CrossRef]

31. Jiang, J.; Zhu, L.; Zhu, L.; Zhang, H.; Zhu, B.; Xu, Y. Antifouling and antimicrobial polymer membranes based on bioinspired polydopamine and strong hydrogen-bonded poly(N-vinyl pyrrolidone). ACS Appl. Mater. Interfaces 2013, 5, 12895-12904. [CrossRef] [PubMed]

32. Wang, C.; Li, X.; Wang, H.; Fei, G.; Wen, H. In-situ polyurethane/polyacrylate microemulsion formation: The effects of acrylic content in wood coating application. Iran. Polym. J. 2017, 26, 753-763. [CrossRef]

33. Ma, G.; Shen, Y.; Gao, R.; Wang, X. Micromorphology and adhesive properties of sulfonated polyurethane/ polyacrylate emulsions prepared by surfactant-free polymerization. J. Polym. Res. 2017, 24. [CrossRef]

34. Jiang, W.; Grozea, C.M.; Shi, Z.; Liu, G. Fluorinated raspberry-like polymer particles for superamphiphobic coatings. ACS Appl. Mater. Interfaces 2014, 6, 2629-2638. [CrossRef]

35. Cheng, Y.B.; Wang, Z.G. Fluorinated poly(isobornyl methacrylate-co-butyl acrylate) core-shell latex nanoparticles: Synthesis, morphology and wettability of films. Polymer 2013, 54, 3047-3054. [CrossRef]

36. Wang, X.R.; Shen, Y.D.; Lai, X.J. Micromorphology and mechanism of polyurethane/polyacrylate membranes modified with epoxide group. Prog. Org. Coat. 2014, 77, 268-276. [CrossRef]

(C) 2020 by the authors. Licensee MDPI, Basel, Switzerland. This article is an open access article distributed under the terms and conditions of the Creative Commons Attribution (CC BY) license (http://creativecommons.org/licenses/by/4.0/). 